\title{
ENERGY OF POWER SPECTRAL DENSITY FUNCTION AND WAVELET ANALYSIS OF ABSOLUTE PRESSURE FLUCTUATION MEASUREMENTS IN FLUIDIZED BEDS
}

\author{
M. C. SHOU and L. P. LEU* \\ Department of Chemical Engineering, National Taiwan University, Taipei, Taiwan
}

\begin{abstract}
7 he standard deviation of pressure fluctuations is always as a benchmark to characterize fluidized bed, especially in identifying the transition velocities and flow regimes. In this study, the energy of power spectral density function (PSDF) was proved to be a new alternative tool to effectively analyse the pressure fluctuations. Also, the wavelet analysis was significant to deal with the signals in multi-resolution decomposition and in identification of transition velocities and flow regimes. The results from the normalized energy of PSDF and wavelet analysis are in good agreement with the standard deviation analysis.
\end{abstract}

Keywords: fluidized bed; transition velocity; pressure fluctuations; turbulent fluidized bed; standard deviation; power spectral density function; wavelet analysis.

\section{INTRODUCTION}

Gas-solid fluidized bed reactors have been widely applied in the industrial application. The existence of different flow regimes in a gas-solids fluidized bed has been discussed. By different measurement techniques and analytical methods, the transition velocities can be determined to indicate the flow regimes. However, due to influencing factors such as gas/solid properties, operating temperature and pressure, the existence of transition velocities arises controversies and makes it hard to determine the flow regimes exactly. Thus, several measurement techniques including visual observation, local capacitance, pressure fluctuations and local and overall bed expansion have been utilized to determine the transition from bubbling regime to turbulent regime. This study focuses on the measurement technique of the pressure fluctuation signals.

The first quantitative study of local voidage, voidage fluctuations and pierced void measured by capacitance probes seems to have been performed by Lanneau (1960). The first transition criterion from bubbling to turbulent fluidization was proposed by Yerushalmi et al. (1978). The gas velocity, $U_{\mathrm{c}}$ at which the standard deviation of pressure fluctuations reached a maximum was said to mark the beginning of the transition to turbulent fluidization, while $U_{\mathrm{k}}$, where the standard deviation of the pressure fluctuations levels off, was said to denote the end of the transition. In recent years, $U_{\mathrm{c}}$ has been widely adopted to define the transition to turbulent fluidization ( $\mathrm{Bi}$ et al.,

* Correspondence to: Professor L. P. Leu, Department of Chemical Engineering, National Taiwan University, Taipei 106-17, Taiwan.

E-mail: 1leulii@ntu.edu.tw
2000). However, $U_{\mathrm{k}}$ often cannot be found (e.g., Satija and Fan, 1985; Rhodes and Geldart, 1986) and depends on the system used to return particles captured after being carried out of the bed (Bi and Grace, 1995) and measurement probe location (Chehbouni et al., 1994). On the other hand, Chehbouni et al. (1994) found that $U_{\mathrm{k}}$ could be determined from differential pressure measurement, but not from absolute pressure measurement. Nowadays, the controversy on discussing the hydrodynamics of the flow regimes still exists, even the confusion of the definition of transport velocity (Avidan and Yerushalmi, 1982; Bi et al., 1995; Grace, 2000).

Also, in recent studies, wavelet analysis has been proven to be a very efficient and effective tool in signal processing (Bruce and Gao, 1996). Fan et al. (1990) were the first to apply the concept of Fractional Brownian Motion (FBM) for analysing pressure fluctuations in a gas-liquid-solid fluidized bed in terms of Hurst rescaled range analysis. He et al. (1997) proposed that the pressure fluctuations in a gas-solid fluidized bed could be decomposed into a FBM and Gaussian White Noise (GWN). $\mathrm{Lu}$ and $\mathrm{Li}$ (1999) and Guo et al. (2002) also employed wavelet analysis to investigate the dynamics of pressure fluctuation in a bubbling fluidized bed. Park et al. (2001) proved that the time series of pressure fluctuation signals were analysed by means of discrete wavelet transform coefficients and multi-resolution decomposition. Zhao and Yang (2003) used wavelet transform, Hurst analysis, multi-scale resolution and time-delay embedding to deal with pressure fluctuations for characterizing the fluidized bed.

In this study, we analysed absolute pressure fluctuations measured above and below the distributor whereas much of the literature measured the pressure fluctuations only above 
the distributor. The aim of the study was to characterize the flow regimes and transition velocities by means of the multiple analyses: standard deviation analysis, PSDF, the energy of PSDF and wavelet analysis. Among these analyses, effective tools, the energy of PSDF and wavelet analysis, were put to proof.

\section{ANALYTICAL METHODS}

\section{Time Domain Analysis}

The standard deviation of the measured pressure fluctuation signals, $p_{\mathrm{i}}$ is defined mathematically as follows:

$$
\text { S.D. }=\sqrt{\frac{1}{n-1} \sum_{i=1}^{n}\left(p_{\mathrm{i}}-\bar{p}\right)^{2}}, \quad i=1,2,3, \ldots, n
$$

with the average pressure,

$$
\bar{p}=\frac{1}{n} \sum_{i=1}^{n} p_{\mathrm{i}}
$$

\section{Frequency Domain Analysis}

The PSDF $P_{\mathrm{xx}}(\omega)$ of signal $x(t)$ has been derived from the autocorrelation function as (Bendat and Piersol, 1980)

$$
P_{\mathrm{xx}}(\omega)=\frac{2}{\pi} \int_{0}^{\infty} R_{\mathrm{xx}}(\tau) \cos \omega \tau \mathrm{d} \tau
$$

where $R_{\mathrm{xx}}(\tau)$ is the autocorrelation function of $x(t)$, which can be expressed as

$$
R_{\mathrm{xx}}(\tau)=\lim _{T \rightarrow \infty} \frac{1}{T} \int_{0}^{T} x(t) x(t+\tau) \mathrm{d} t
$$

\section{Wavelet Analysis}

In wavelet analysis, we can use linear combination of Daubechies (db3) wavelet function to represent pressure fluctuation signals.

First, the wavelet transform of a continuous signal $x(t)$ can be defined as

$$
W_{\mathrm{f}}(a, b)=\frac{1}{\sqrt{|a|}} \int_{-\infty}^{+\infty} x(t) \varphi_{\mathrm{a}, \mathrm{b}}^{*}\left(\frac{t-b}{a}\right) \mathrm{d} t
$$

where $W_{\mathrm{f}}(a, b)$ is the wavelet coefficient, $\varphi_{\mathrm{a}, \mathrm{b}}^{*}(t)$ is a basic wavelet function, $a$ and $b$ are the continuous dilation and translation parameters, respectively, they take values in the range of the amplitude function $-\infty<a, b<\infty$ with $a \neq 0$.

Wavelet functions form a family of functions with high frequency and small duration that are all normalized dilations and translation of a prototype 'wavelet base' function. Thus

$$
\varphi_{\mathrm{a}, \mathrm{b}}(t)=\frac{1}{\sqrt{|a|}} \varphi\left(\frac{t-b}{a}\right)
$$

An original signal is decomposed into its approximations and details with different frequency bands by means of wavelet transform. The decomposition process is repeated until the desired decomposition level, $J$, is reached. The orthogonal wavelet series approximate a continuous signal $x\left(t_{\mathrm{i}}\right)$ expressed as

$$
x\left(t_{\mathrm{i}}\right) \approx A_{\mathrm{j}}\left(t_{\mathrm{i}}\right)+D_{\mathrm{j}}\left(t_{\mathrm{i}}\right)+D_{\mathrm{j}-1}\left(t_{\mathrm{i}}\right)+\cdots+D_{1}\left(t_{\mathrm{i}}\right)
$$

where $D_{1}\left(t_{\mathrm{i}}\right), D_{2}\left(t_{\mathrm{i}}\right), \ldots, D_{\mathrm{j}}\left(t_{\mathrm{i}}\right)$ represent detail signals of multi-resolution decomposition at different resolution $2^{\mathrm{j}}$, and $A_{\mathrm{j}}\left(t_{\mathrm{i}}\right)$ the approximation signal of multi-resolution decomposition at resolution $2^{\mathrm{j}}$.

As we know, the quality of signal decomposition and reconstruction mainly depend on the choice of the mother wavelet (Bruce and Gao, 1996). Wavelets separate a signal into multi-resolution components. The components at fine and coarse resolutions indicate the fine- and coarse-scale features of the signal. In this study, we use Daubechies (db3) wavelet to calculate pressure fluctuation signals just as Guo et al. (2003) did.

\section{EXPERIMENTS}

The schematic diagram of the experimental setup is shown in Figure 1. The apparatus consists of a riser, an expanded-top section and a cyclone separator. The riser column made of Plexiglas is $10.8 \mathrm{~cm}$ i.d. and $5.75 \mathrm{~m}$ in height; the expanded top section made of stainless steel is $1.5 \mathrm{~m}$ in height and is five-times the cross section area of the riser bed area. According to Avidan and Yerushalmi (1985), the expanded bed section at high gas velocity can reduce the solid entrainments. The entrained particles from the expanded top section are collected by the cyclone separator and are recycled to the riser bed by use of the loop-seal type non-mechanical valve. A perforated plate with fine screen was used as the gas distributor. There were 250 holes of $1.5 \mathrm{~mm}$ in diameter uniformly distributed on the plate, giving an open-area ratio of $4.8 \%$. The bed material used is fluid catalytic cracking (FCC) particles, with an average particle size $71 \mu \mathrm{m}$, and a particle density of $1800 \mathrm{~kg} \mathrm{~m}^{-3}$, i.e., Geldart group A particles (Geldart, 1973), the minimum fluidization velocity for FCC particles, $0.3 \mathrm{~mm} \mathrm{~s}^{-1}$.

The pressure probe used is made of $3 \mathrm{~mm}$ i.d. copper tube. One end of the probe is covered with a fine screen to prevent solid particles flowing into the probe, and the other end of the probe is connected to a pressure transducer. The continuous pressure signal from the pressure transducer is amplified and sent to a personal computer for recording and further analysis. Data acquisition is performed 100 readings per second, and the total number of readings is equal to 10000 . The pressure fluctuation signals are analysed by means of the standard deviation, power spectral density function and wavelet analysis. The absolute pressure tap is mounted flush with the wall of the column at four pressures tap positions $-4,14,30,50 \mathrm{~cm}$ from the distributor.

To obtain sufficient experimental evidence, we measured pressure fluctuation signals from different static bed heights varying from $0.5 \mathrm{~m}$ to $0.7 \mathrm{~m}$. 


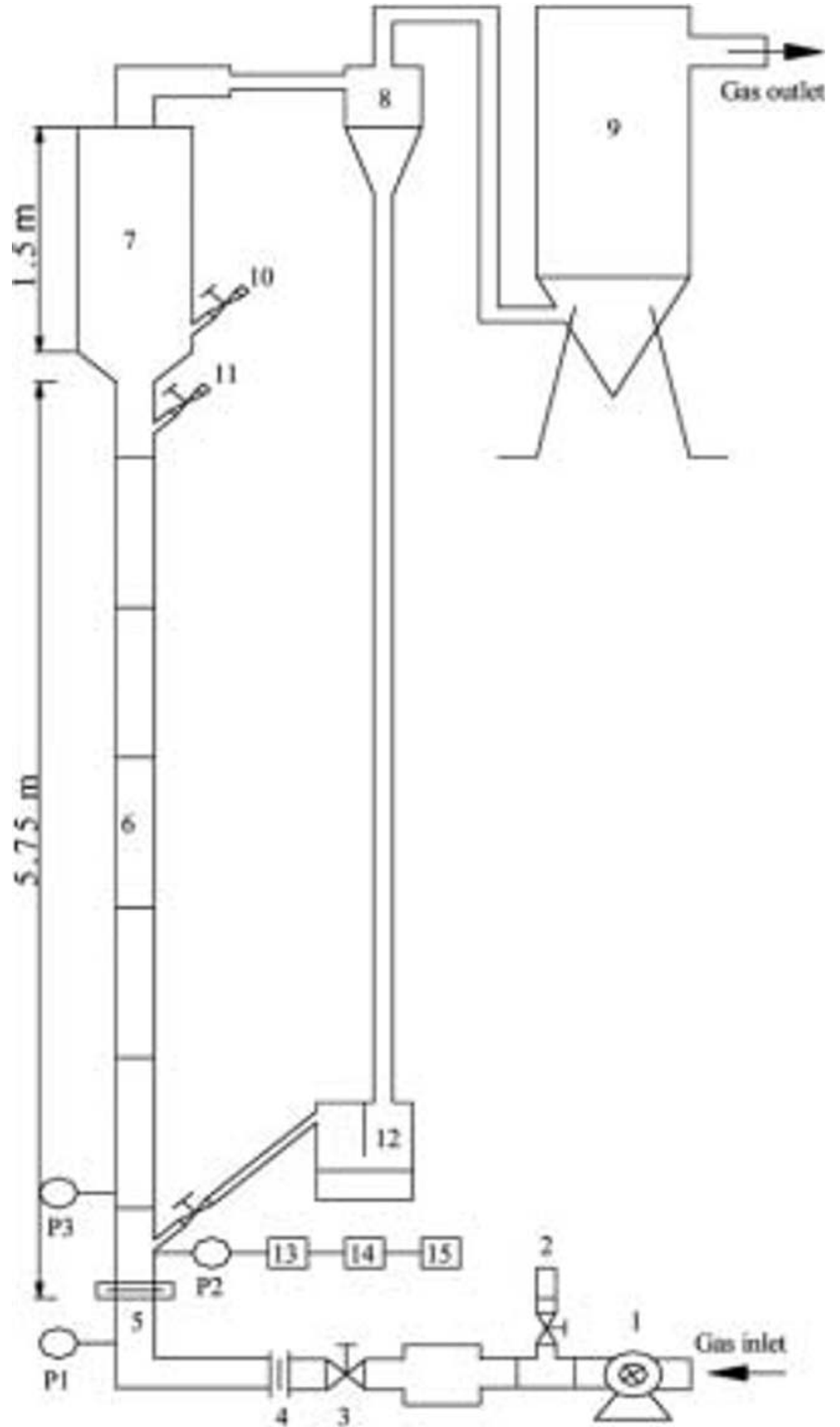

Figure 1. Experimental setup of expanded-top fluidized bed: (1) blower; (2) safety valve; (3) gate valve; (4) orifice meter; (5) distributor; (6) riser bed; (7) expanded top section; (8) cyclone separator; (9) bag filter; (10), (11) gate valve; (12) loop-seal; (13) pressure transducer; (14) amplifier; (15) computer \& AD/DA card; P1, P2; pressure tap.

\section{RESULTS AND DISCUSSION}

Various kinds of measurements in literature have been used to predict the transition of flow regimes. In literature studies (Lee and Kim, 1988; Schnitzlein and Weinstein, 1988; Mori et al., 1988; Sun and Chen, 1989), the absolute pressure fluctuation measurements above the distributor are usually applied to obtain the pressure fluctuation signals. In this study, an absolute pressure probe was used to measure the pressure fluctuation signals at the measuring position not only above but also below the distributor. We used the standard deviation, PSDF, the normalized PSDF of pressure fluctuation signals, and wavelet analysis to analyse the pressure fluctuation signals, as a function of the superficial gas velocity for FCC particles.

\section{Standard Deviation of Pressure Fluctuations}

Figure 2 shows the measured standard deviation of the pressure fluctuation signals, which change with the superficial gas velocity at axial positions $(-4,14,30$, and $50 \mathrm{~cm}$ ) above the distributor by an absolute pressure probe. When the pressure fluctuation signals were measured below the distributor, at $-4 \mathrm{~cm}$ by an absolute pressure probe, both $U_{\mathrm{c}}=1.0 \mathrm{~m} \mathrm{~s}^{-1}$ and $U_{\mathrm{k}}=1.65 \mathrm{~m} \mathrm{~s}^{-1}$ were found. The result is different from those of Chehbouni et al. (1994) who proposed that the transition velocities could not be obtained from absolute pressure measurement. Besides, for probe above the distributor, $U_{\mathrm{c}}=1.15 \mathrm{~m} \mathrm{~s}^{-1}$ was obtained, close to the value obtained below the distributor, whereas the leveling-off of the standard deviation of the pressure fluctuations was not obtained by measuring above the distributor, at 30 and $50 \mathrm{~cm}$ except for an ambiguous $U_{\mathrm{k}}$ obtained at $14 \mathrm{~cm}$.

In summary, $U_{\mathrm{c}}$ and $U_{\mathrm{k}}$ were found by absolute pressure probe locating below the distributor. Meanwhile, $U_{\mathrm{c}}$ was found and $U_{\mathrm{k}}$ was ambiguous by an absolute pressure probe locating above the distributor. As seen in the figure, the variation of the transition velocities could describe the flow regimes. With increasing superficial gas velocity, the bubbles became larger and larger, and then slugging phenomenon appeared over coalescence. The more violent pressure fluctuations became, the more serious slugging the bubbles had. When bubbles reached a maximum stable size, the standard deviation of the pressure fluctuations reached the maximum and the corresponding superficial gas velocity was denoted as $U_{\mathrm{c}}$. $U_{\mathrm{c}}$ clarified a change from bubbling to turbulent fluidization. Therefore, $U_{\mathrm{c}}$ was considered as the onset of turbulent flow regime. As the superficial gas velocity increased slowly, non-uniformity of two-phase (dense-dilute) system gradually vanished and tended to form a homogeneous state. The transition point where the standard deviation of pressure fluctuations leveled off was the transition velocity, $U_{\mathrm{k}}$. Thus, $U_{\mathrm{k}}$ was denoted the end of the turbulent bed and the beginning of the fast bed.

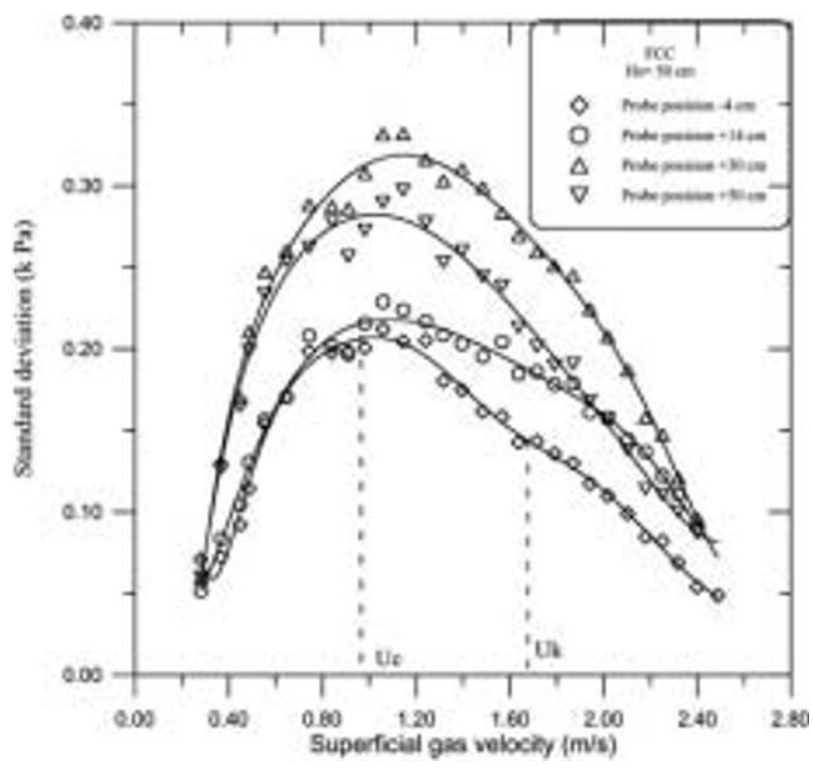

Figure 2. Standard deviation of pressure fluctuations at the static bed, $50 \mathrm{~cm}$, in height, measured by an absolute pressure probe at the different measurement positions $(-4,14,30,50 \mathrm{~cm}$ above the distributor). 
To make sure that the ambiguous $U_{\mathrm{k}}$ did exist, the following analytic methods were studied.

\section{Power Spectral Density Function (PSDF)}

PSDF is applied to analyse and characterize the hydrodynamics of fluidized beds. The method is utilized to describe the dominant frequency. A wide band spectrum is considered to signify an increase in the number of bubbles, while a narrow band with sharp peaks either signifies a single bubble or slugging bed behaviour.

Figure 3 shows the PSDF of the measured pressure fluctuations below the distributor, at $-4 \mathrm{~cm}$. It shows the PSDF for a wide range of gas velocities covering different fluidization
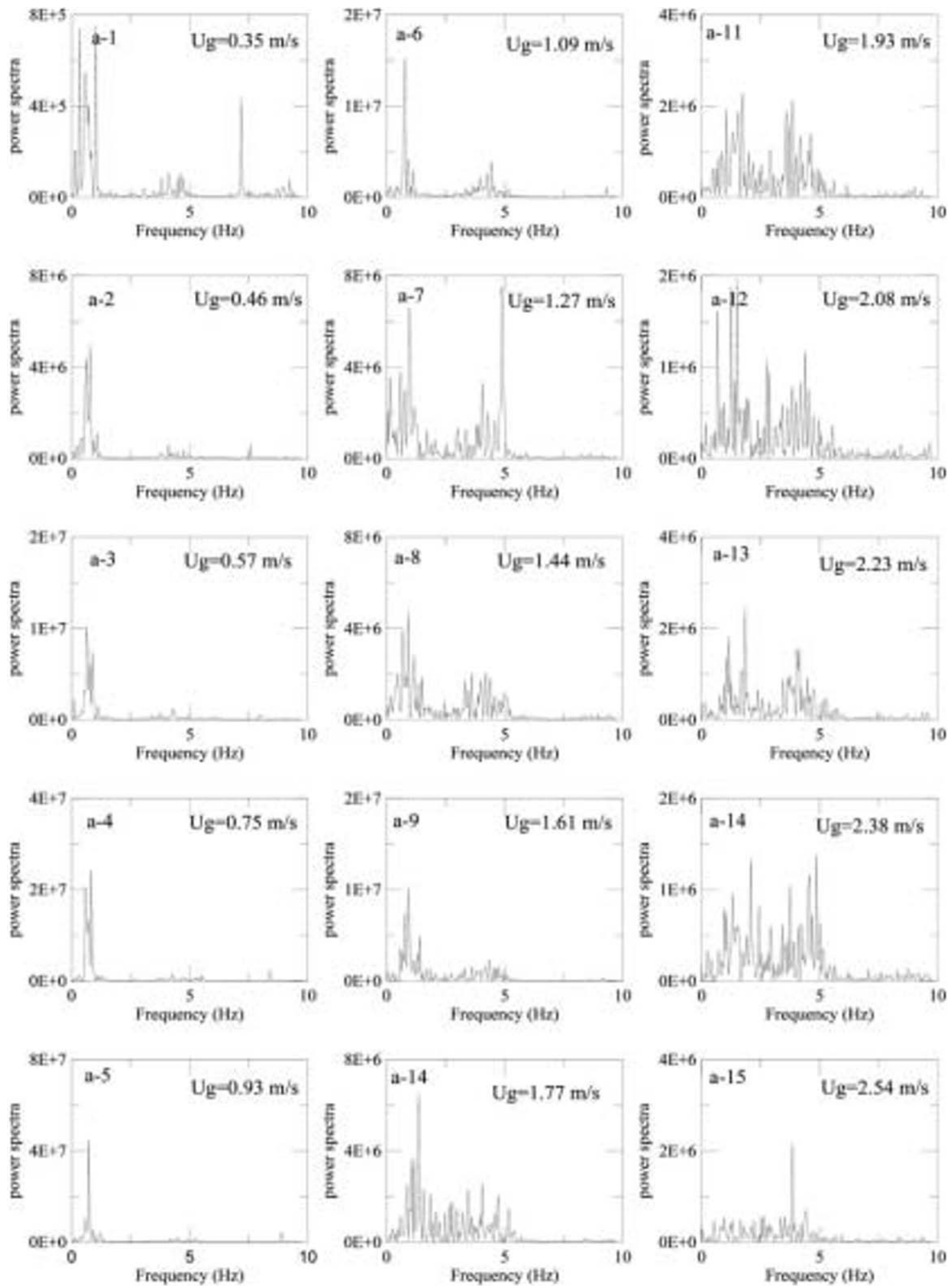

Figure 3. The power spectral density function $\left(\mathrm{Pa}^{2} / \mathrm{Hz}\right)$ at different superficial gas velocity obtained below the distributor, at $-4 \mathrm{~cm}$, and the static bed $50 \mathrm{~cm}$, in height, by an absolute pressure probe. 

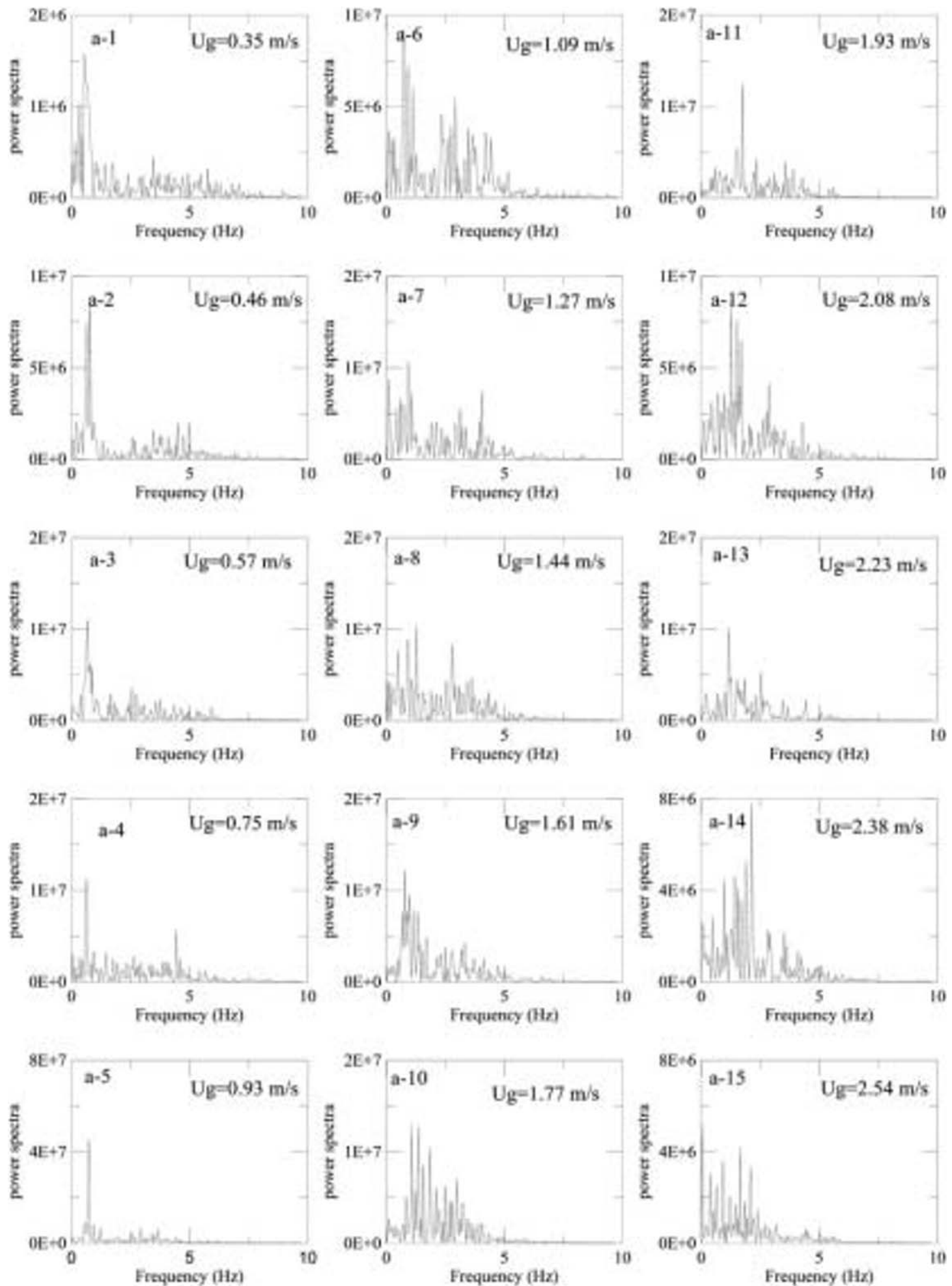

Figure 4. The power spectral density function $\left(\mathrm{Pa}^{2} / \mathrm{Hz}\right)$ at different superficial gas velocities obtained above the distributor, at $14 \mathrm{~cm}$, and the static bed $50 \mathrm{~cm}$, in height, by an absolute pressure probe.

regimes. The band spectrum and magnitude vary with the gas velocity. When $U_{\mathrm{g}}<0.93 \mathrm{~m} \mathrm{~s}^{-1}$, a narrow-banded spectrum was observed [see Figures 3(a-1)-(a-5)]. It indicated that the flow regime was from bubbling to turbulent fluidization. $U_{\mathrm{c}}$, the maximum point, marked the end of the bubbling fluidized bed and the onset of the turbulent fluidized bed. The dominant frequency was approximately $0.5-0.75 \mathrm{~Hz}$ and its peak energy increased with the increase of the superficial gas velocity. When $1.09 \mathrm{~m} \mathrm{~s}^{-1}<U_{\mathrm{g}}<1.93 \mathrm{~m} \mathrm{~s}^{-1}$, the power spectra became broad and two dominant peak frequencies were observed [see Figures 3(a-6)-3(a-11)]. With the increase of the gas velocity, one dominant peak frequency, $3.5 \sim 4.5 \mathrm{~Hz}$ increased and its peak energy decreased. When $U_{\mathrm{g}}>2.08 \mathrm{~m} \mathrm{~s}^{-1}$, the power spectra became broader 


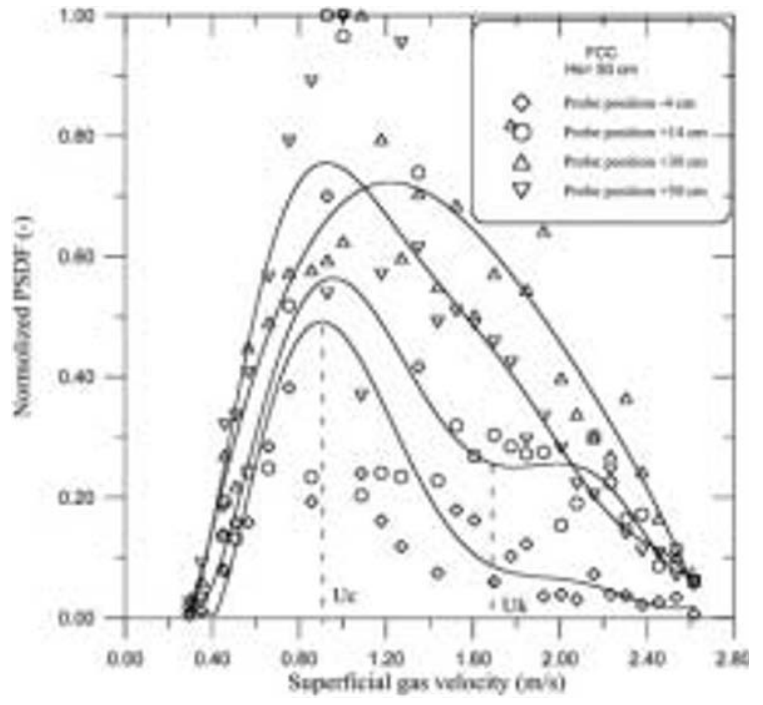

Figure 5. The normalized PSDF, at static bed $50 \mathrm{~cm}$, in height, measured by four absolute pressure probes, at $-4,14,30$, and $50 \mathrm{~cm}$ above the distributor. and multi-peaks appeared along with the decrease of the energy of peaks.

Figure 4 shows the PSDF of the measured pressure fluctuations at $14 \mathrm{~cm}$ above the distributor. At the low gas velocity, when $U_{\mathrm{g}}<0.93 \mathrm{~m} \mathrm{~s}^{-1}$, a narrow-banded spectrum was observed [see Figures 4(a-1)-(a-5)]. At higher gas velocity, when $U_{\mathrm{g}}>1.09 \mathrm{~m} \mathrm{~s}^{-1}$, the power spectra became broad with a moderate spectral magnitude and multipeaks were noticed [see Figures 4(a-6)-(a-15)], as Makkawi and Wright (2002) discussed The dominant peak frequency showed little change and the power spectral magnitude was considerably lower.

Namely, two trends were seen as a function of $U_{\mathrm{g}}$. When $U_{\mathrm{g}}<U_{\mathrm{c}}$, the amplitude of the pressure fluctuations and the energy level of the spectral densities increased with the superficial gas velocity. Because of the formation and coalescence of bubbles and slugs, fluctuations became more and more regular and formed a smaller range of dominant frequency. Then, above $U_{\mathrm{c}}$, in the turbulent regime, fluctuations became more and more irregular with the increase of the superficial gas velocity. When the superficial

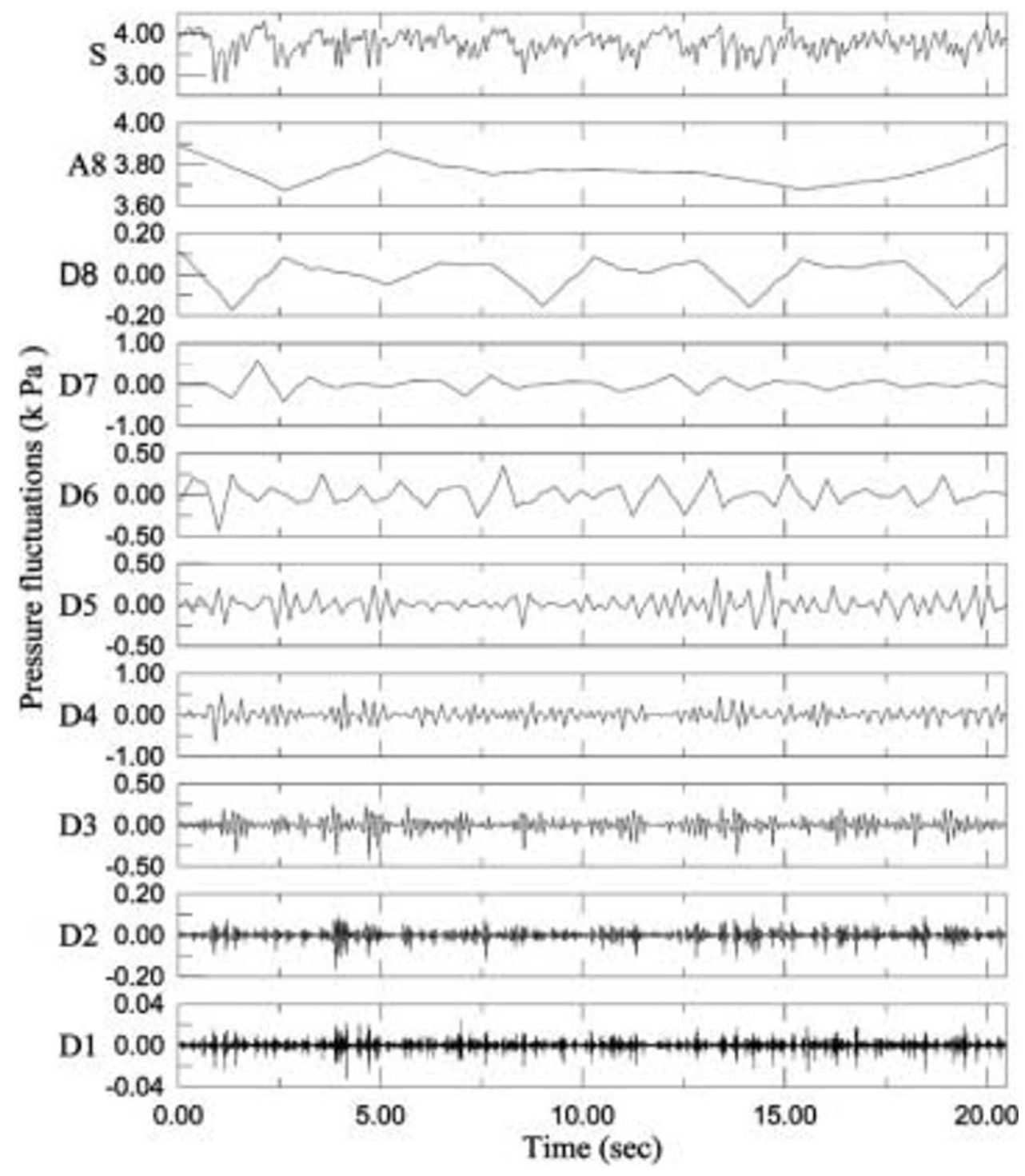

Figure 6. Eight decomposed resolution detail scales of the pressure fluctuation signals. 

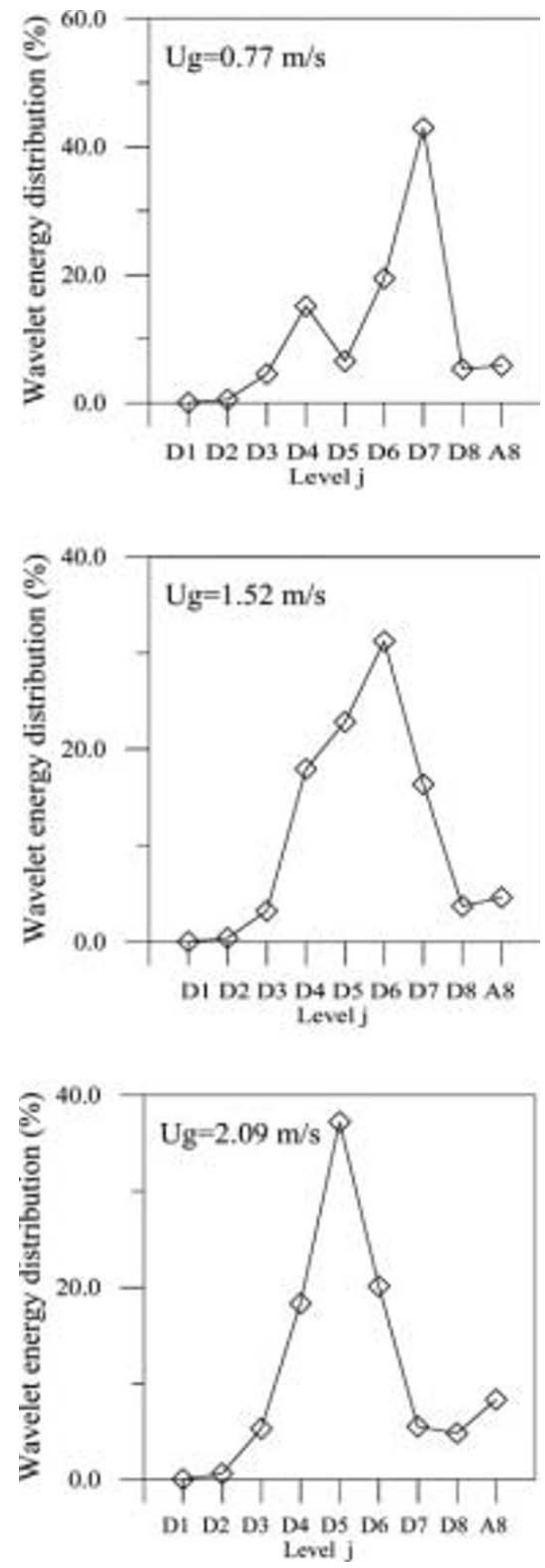

Figure 7. Wavelet energy (\%) profiles for pressure fluctuation signals at different gas velocities.

gas velocity increased, the amplitude of the pressure fluctuations decreased and the energy of spectral densities also decreased. No dominant frequency still existed. Flow irregularity appeared and all fluctuations vanished.

From the experimental result, it was found that a precise estimate of a transition velocity could not be extracted from the power spectral analysis. This was mainly due to the similarity of various spectral shapes at the broad spectral distribution. Though an obvious peak appeared at every single frequency dominant, it was hard to clarify the dominant frequency peak in broad-banded power spectra.

The above result agreed with those drawn by Chehbouni et al. (1994) who also utilized PSDF as an analytical method to analyse the differential pressure fluctuation signals. Thus, we tried to utilize the energy of PSDF to analyse the pressure fluctuation signals and made sure the existence of the transition velocities in characterizing the fluidized bed.

\section{The Energy of Power Spectral Density Functions (PSDF)}

Chehbouni et al. (1994) focused on the peak variation of the superficial velocity instead of exploring the energy of power spectral density function. However, this study put stress on the energy variation of superficial gas velocity. Some procedures were described as follows:

(1) We try to gain the energy of PSDF.

(2) The maximum energy of peak dominant was found and recorded as $\left(e_{\max . \mathrm{i}}\right)$.

(3) The steps from (1) to (2) were repeated and formed a vector, $\vec{E}$

$\overrightarrow{\mathrm{E}}=\left(e_{\max .1}, e_{\max .2}, e_{\max .3}, \ldots, e_{\max . \mathrm{n}}\right)$

(4) From the vector $\vec{E}$, we found an element of maximum value represented $e_{\mathrm{MAX}}$.

(5) Moreover, we normalized the vector of $\overrightarrow{\mathrm{E}}$ by $e_{\mathrm{MAX}}$.

$$
\overrightarrow{\mathrm{E}_{\mathrm{norm} .}}=\left(e_{\max .1} / e_{\mathrm{MAX}}, e_{\max .2} / e_{\mathrm{MAX}}, \ldots, e_{\max . \mathrm{n}} / e_{\mathrm{MAX}}\right)
$$

Figure 5 shows the result of normalized energy of PSDF. The hydrodynamics of the fluidized bed was characterized successfully similar to the result obtained by the standard deviation of the pressure fluctuations. We clarified the existence of $U_{\mathrm{c}}$, when $U_{\mathrm{c}}$ was found to be $0.9 \mathrm{~m} \mathrm{~s}^{-1}$ at the different positions $(-4,14,30,50 \mathrm{~cm})$ by use of an absolute pressure probe. Also, we obtained a distinct level off, $U_{\mathrm{k}}=1.6 \mathrm{~m} \mathrm{~s}^{-1}$, by use of an absolute pressure probe at $-4,+14 \mathrm{~cm}$ above the distributor. At other positions (30, $50 \mathrm{~cm}$ above the distributor), there was an ambiguous $U_{\mathrm{k}}$. When superficial gas velocity increased to $U_{\mathrm{c}}=0.9 \mathrm{~m} \mathrm{~s}^{-1}$, bubbles reached maximum stable size. And then the pressure fluctuations agitated violently, gradually decayed and finally leveled off to $U_{\mathrm{k}}=1.6 \mathrm{~m} \mathrm{~s}^{-1}$. When massive bubbles began to break up, the flow regime transformed from bubbling to turbulent fluidization. Meanwhile, bubble splitting became dominant. In this analysis, it was found that the existence of $U_{\mathrm{c}}$ and $U_{\mathrm{k}}$ depended on the magnitude of the energy. The energy of PSDF would be a new alternative tool to effectively analyse the pressure fluctuations. The result was also in agreement with the standard deviation analysis.

\section{Wavelet Analysis}

A peak or peaks in the power spectral density function described the major periodic component or components in 


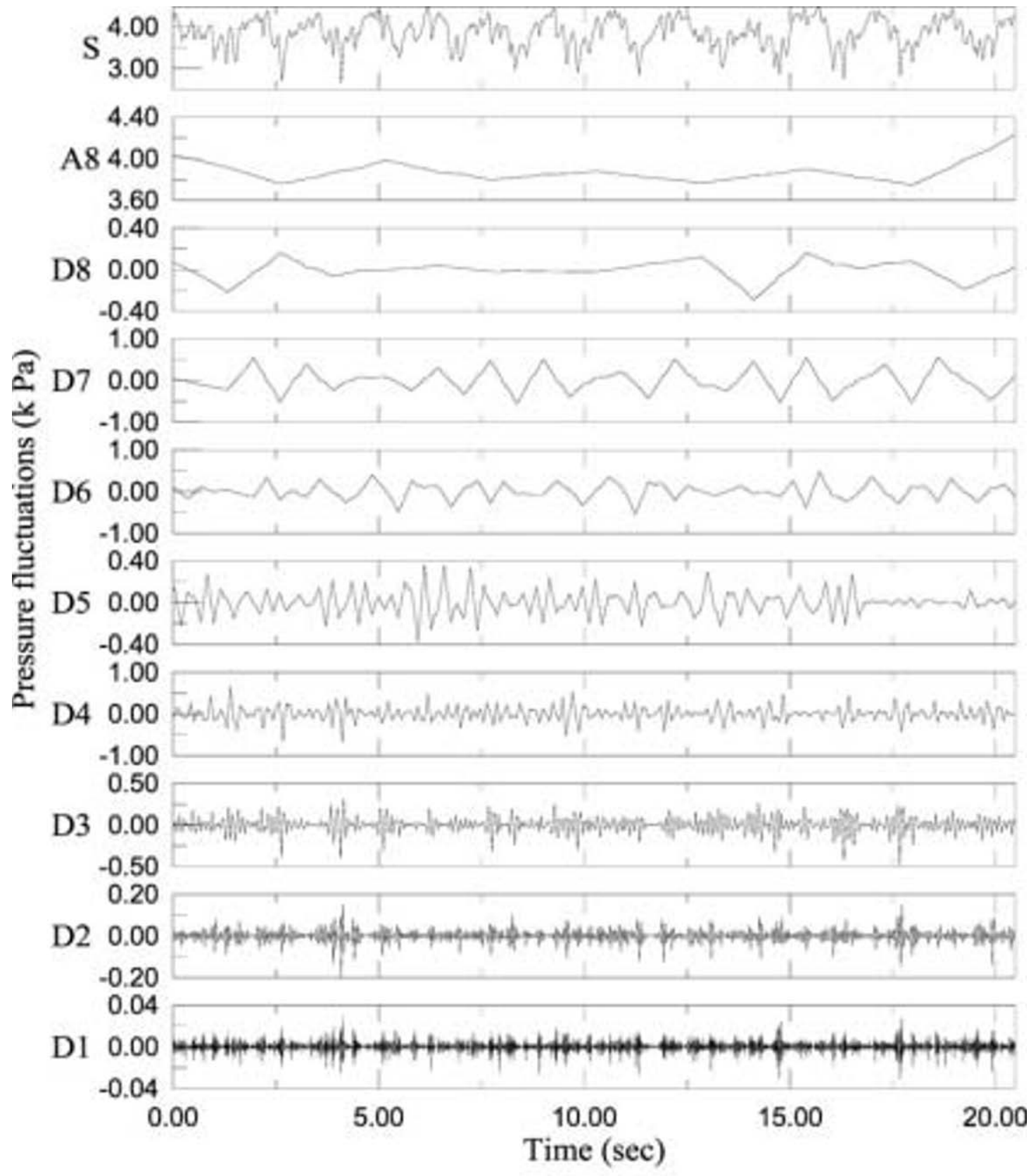

(a)

Figure 8. Wavelet multi-resolution decomposition of fluctuating pressures at different superficial gas velocities (a) $U_{\mathrm{g}}=0.77 \mathrm{~m} \mathrm{~s}$, (b) $U_{\mathrm{g}}=1.52 \mathrm{~m} \mathrm{~s}{ }^{-1}$, (c) $U_{\mathrm{g}}=2.09 \mathrm{~m} \mathrm{~s}^{-1}$.

the random variable (Mori et al., 1988). When the bubble size became bigger, the peak got lower. The peaks were defined as bubbles. The major frequency was obtained from power spectral density function but did not reveal the bubbling movement over time. The reason is that Fourier transform is localized only in frequency but not in time.

Figure 6 shows raw pressure data and their decomposed signals. The pressure fluctuation signals in fluidized beds were decomposed into eight resolution detail scales with different frequency bands. The original signals were resolved by order on the basis of sample frequency. The original signal was plotted in the top row, and the reconstructed wavelets were in the remaining rows. The original signal $S$ can be separated into the reconstructed detail, $D_{1}$ and approximation, $A_{1}$. The approximation, $A_{1}$, can be decomposed into $A_{2}$ and $D_{2}$ and the like. In this way, $D_{1}$ is the detail component of the original signal $S$, while $D_{2}$ is the detail component of $A_{1}$ and $D_{3}$ is the detail component of $A_{2}$ and so forth. The reconstructed wavelets spread from fine scale $D_{1}$ in the bottom row to coarse scale $D_{8}$ in the third rows and $A_{8}$, in the second row. The fine scale detail was almost dominated by the noise 


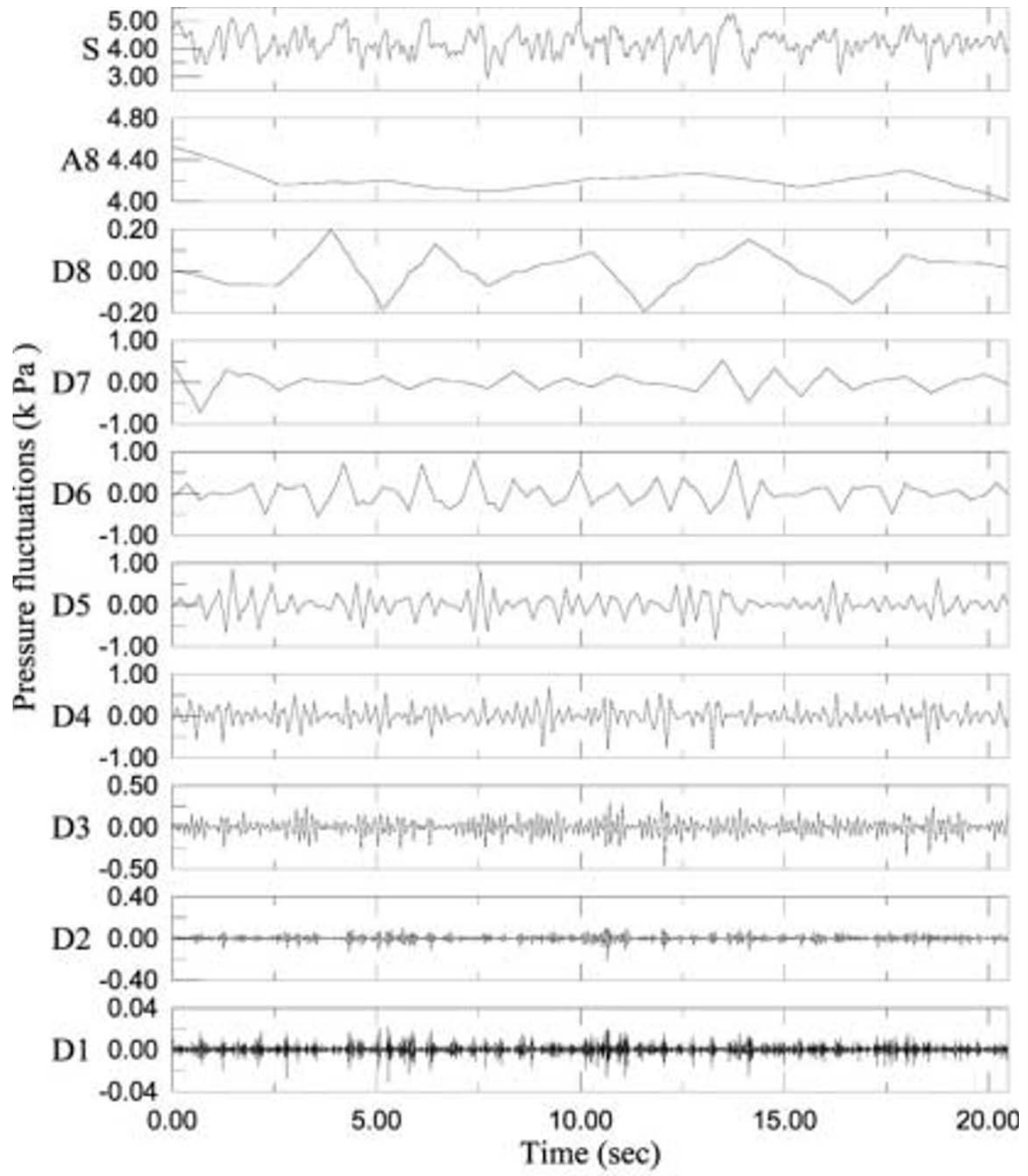

(b)

Figure 8. Continued.

(higher frequency). The coarse scale described the low frequency oscillations in the pressure signal, large bubbles. Namely, the fine scale corresponded to information about the high frequency of the original signal, and the coarse scale corresponded to information about the low frequency of the original signal.

The energy of a digitized signal is defined as the squared sum of amplitude as follows:

$$
W=\sum_{i=1}^{n}\left|x\left(t_{\mathrm{i}}\right)\right|^{2}
$$

Let $W_{\mathrm{j}}^{\mathrm{D}}, W_{\mathrm{J}}^{\mathrm{A}}$ be defined as level energy, which is the decomposed cumulative energy of different level $j$ detail signals and level $J$ approximation signal.

$$
\begin{aligned}
W_{\mathrm{j}}^{\mathrm{D}} & =\sum_{i=1}^{n}\left|D_{\mathrm{j}}\left(t_{\mathrm{i}}\right)\right|^{2} i=1,2, \ldots, n, j=1,2, \ldots, J \\
W_{\mathrm{J}}^{\mathrm{A}} & =\sum_{i=1}^{n}\left|A_{\mathrm{J}}\left(t_{\mathrm{i}}\right)\right|^{2}
\end{aligned}
$$




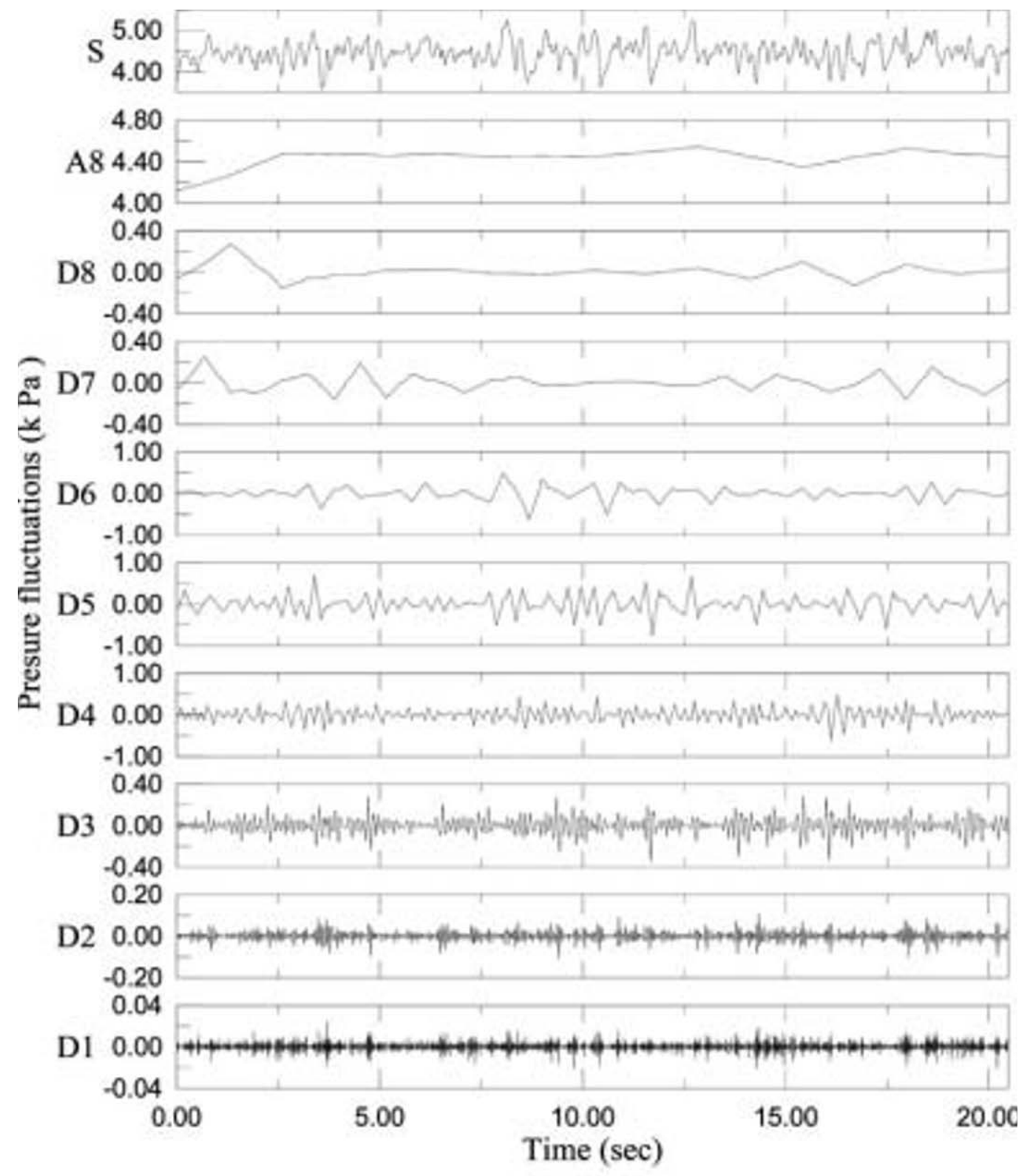

(c)

Figure 8. Continued.

with the total energy given by

$$
W_{\mathrm{T}}=\sum_{j=1}^{J} W_{\mathrm{j}}^{\mathrm{D}}+W_{\mathrm{J}}^{\mathrm{A}}
$$

To be more precise, the ratio of energy at different levels to the total energy is more important in showing how the energy is displayed at different levels. Let

$$
\begin{aligned}
& R_{\mathrm{j}}^{\mathrm{D}}=\frac{W_{\mathrm{j}}^{\mathrm{D}}}{W_{\mathrm{T}}} \times 100 \%, \quad j=1,2, \ldots, J \\
& R_{\mathrm{J}}^{\mathrm{A}}=\frac{W_{\mathrm{J}}^{\mathrm{A}}}{W_{\mathrm{T}}} \times 100 \%
\end{aligned}
$$

In this manner, $R_{\mathrm{j}}^{\mathrm{D}}$ and $R_{\mathrm{J}}^{\mathrm{A}}$ give a relative wavelet energy distribution in each level. According to equations (12) and (13), the wavelet energy distribution, which is the percentage of the energy of the analysed signal over scales obtained from resolution of discrete wavelet transform, is shown in Figure 7. It shows the variation of energy profiles from coarse (approximation) scale to fine (detail) scale with increasing superficial gas velocities.

Figure 8 illustrates plots of multi-resolution decomposition and the reconstruction. In theory, the wavelet transform separates a signal into different scales or multiresolution levels. The fine scale detail components (i.e., the wavelet transform) $D_{1}$ and $D_{2}$ describe small-scale fluctuations with high frequency oscillations. The coarse scale components (the approximation, the remainder of the original signals through wavelet filter) $D_{8}$ and $A_{8}$ describe lower frequency oscillations. In Figure 8(a) of lower superficial gas velocity $\left(U_{\mathrm{g}}=0.77 \mathrm{~m} \mathrm{~s}^{-1}\right)$, the dominant scale over the experiment time was the $D_{7}$ scale, 

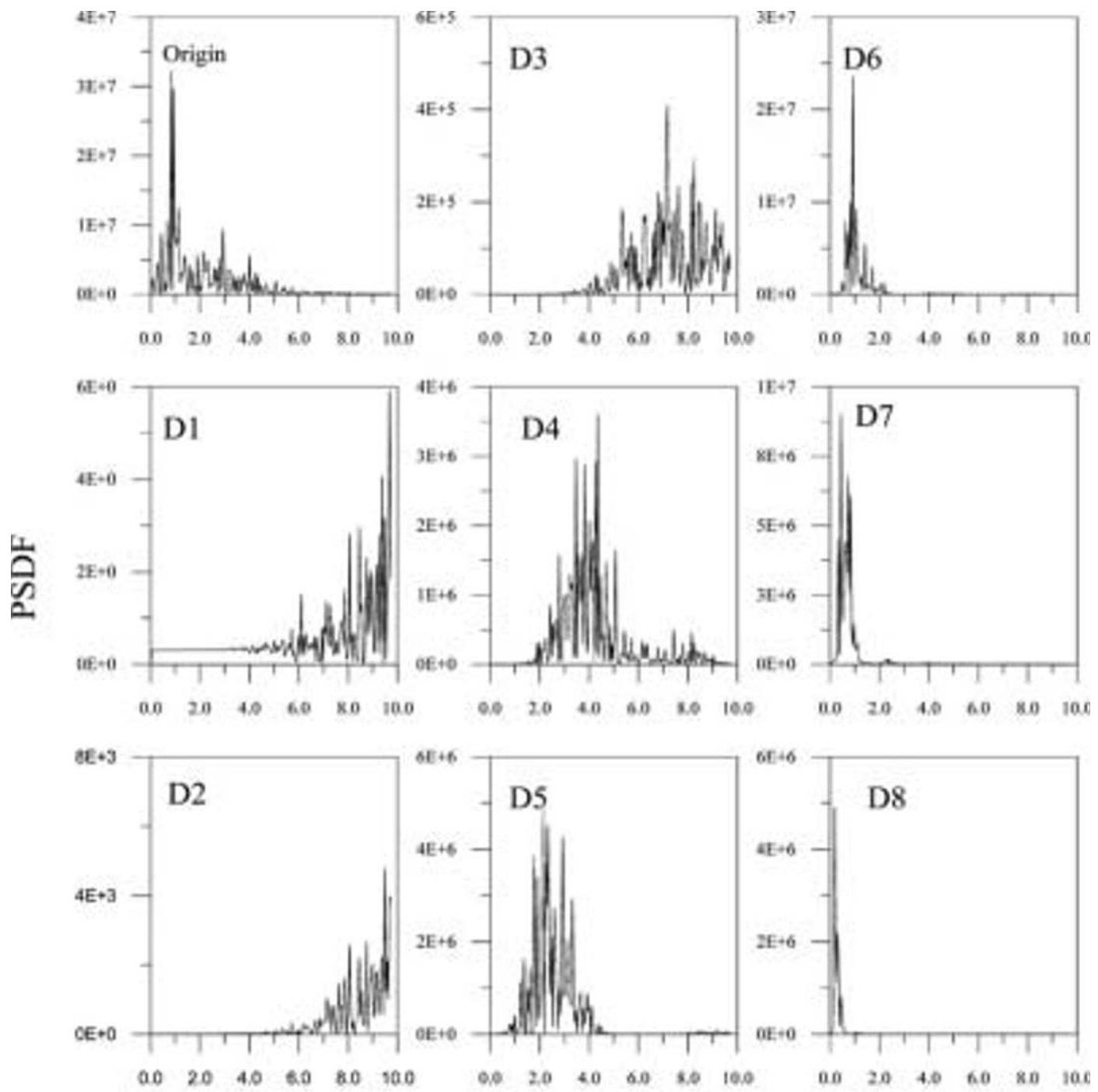

Frequency $(\mathrm{Hz})$

(a)

Figure 9. The PSDF $\left(\mathrm{Pa}^{2} / \mathrm{Hz}\right)$ of multi-resolution decomposition of the pressure fluctuation signals at $U_{\mathrm{g}}=1.52 \mathrm{~m} \mathrm{~s}{ }^{-1} ;\left(\right.$ a) the detail scales, $D_{1}-D_{8}$; (b) the approximation scales, $A_{1}-A_{8}$.

which was coarser than $D_{6}$ in Figure $8(\mathrm{~b})$ of higher superficial gas velocity $\left(U_{\mathrm{g}}=1.52 \mathrm{~m} \mathrm{~s}^{-1}\right)$. Also, in Figure $8(\mathrm{~b})$ of lower superficial gas velocity $\left(U_{\mathrm{g}}=1.52 \mathrm{~m} \mathrm{~s}^{-1}\right)$, the dominant scale over the experiment time was the $D_{6}$ scale, which was coarser than $D_{5}$ in Figure 8(c) of higher superficial gas velocity $\left(U_{\mathrm{g}}=2.09 \mathrm{~m} \mathrm{~s}^{-1}\right)$. At the lower superficial gas velocity, there was a bigger bubble than the one at the higher superficial gas velocity. Thus, it indicated that an increase in the superficial gas velocity made bubbles in the bed finer.

Figure 9 shows the PSDF of multi-resolution decomposition of the pressure fluctuation signals. Figure 9(a) shows the plots of the fine scales and Figure 9(b) shows the approximation scales. From the fine scale, it was found that $D_{7}$ had the same peak of frequency domain as the original signal. But the amplitude of the $D_{7}$ was about ratio 0.3 of the amplitude of the original signal. Through filter bank properties of wavelet transform, a signal was decomposed into sub-signals. Also, the energy and frequency were the main characteristics to describe a wave. From Figure 9(a), $D_{7}$ only presented the frequency instead of the energy. To distinctly describe the properties of the pressure fluctuation signals, the energy was obtained from the extracted approximation scale. Figure $9(\mathrm{~b})$ is the PSDF of the approximation scales. The frequency and the energy from $A_{1}$ to $A_{6}$ stayed the same with those of the original signal. As for $A_{6}$, its frequency was also the same with the original signal but its energy became smaller. Instead of the unstable $A_{6}$, we chose the approximation scales from $A_{1}$ to $A_{5}$ for analysis. We gained the maximum of the approximation scales by PSDF at different superficial gas velocities. Finally, we normalized PSDF.

Figure 10 illustrates the normalized PSDF vs. superficial gas velocity. The absolute pressure probe at $14 \mathrm{~cm}$ above the distributor was used to measure signals, with the bed height of $60 \mathrm{~cm}$. From this figure, we noted that there 


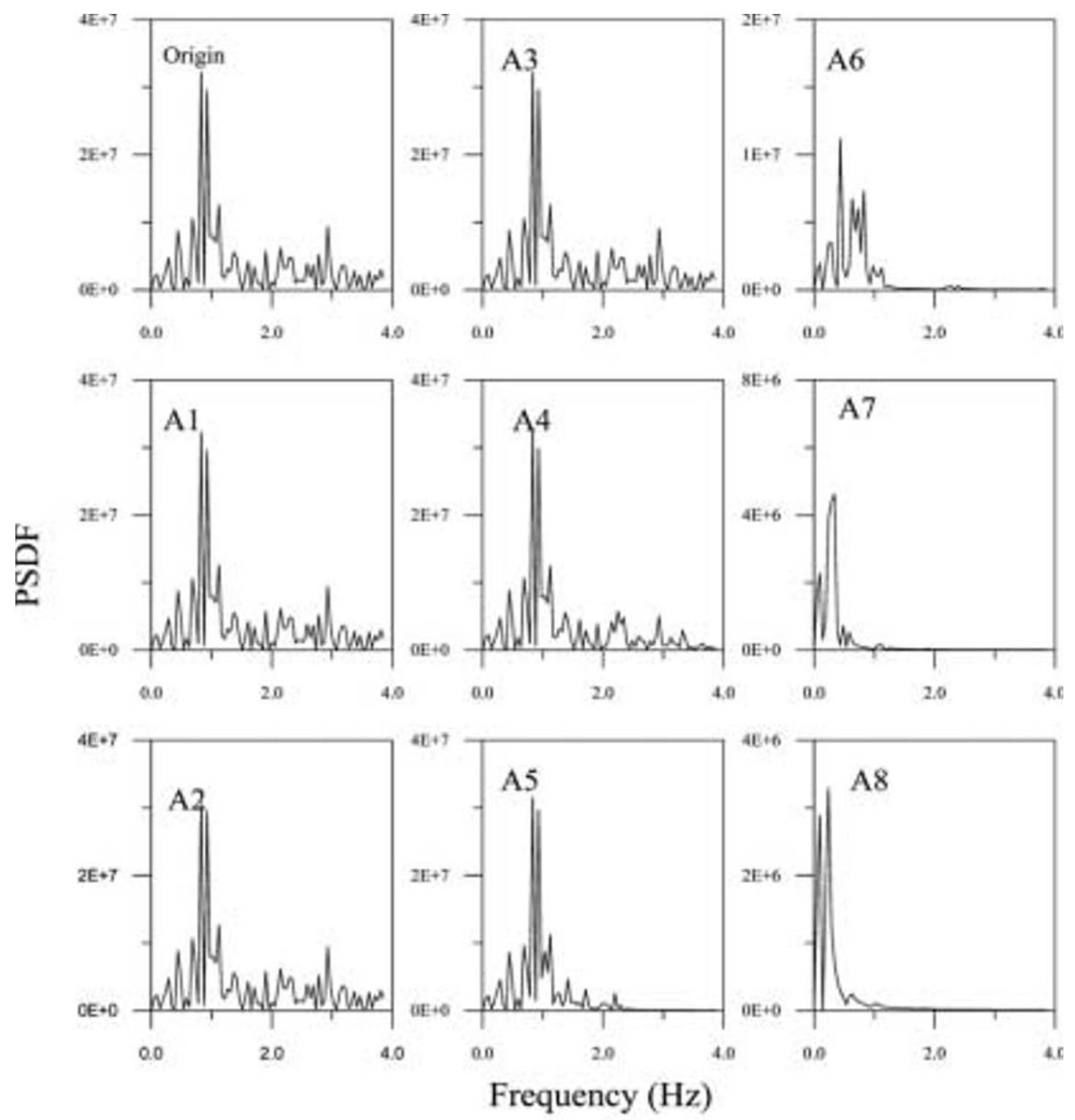

(b)

Figure 9. Continued.

was no much change from $A_{1}$ to $A_{5}$ and it represented the retaining characteristics of original signal. The change beginning with $A_{6}$ presented the change toward another low frequency band. From $A_{1}$ to $A_{5}$, it was obviously found that $U_{\mathrm{c}}$ value was $1.0 \mathrm{~m} \mathrm{~s}^{-1}$ and $U_{\mathrm{k}}$ value was $1.7 \mathrm{~m} \mathrm{~s}^{-1}$.

The result in terms of transition velocity agreed with the analysis of standard deviation of pressure fluctuations and the energy of PSDF. Thus, the result stated that the flow regimes could also be characterized by the wavelet analysis. The signals of low frequency domain characterized the bed traits.

\section{CONCLUSION}

In this paper, the hydrodynamics of the fluidized beds was studied on the basis of analysis of standard deviation,
PSDF and wavelet transform of pressure fluctuation signals. The results follow.

Through the analysis of standard deviation and PSDF of pressure fluctuations, $U_{\mathrm{c}}=0.9 \mathrm{~m} \mathrm{~s}^{-1}$ was obtained by absolute pressure measurement above the distributor and below the distributor. Through the analysis of standard deviation, $U_{\mathrm{k}}$ was ambiguous or could not be found. Through the energy of PSDF, $U_{\mathrm{k}}=1.6 \mathrm{~m} \mathrm{~s}^{-1}$ was obtained for the absolute pressure measurement above the distributor and below the distributor, though an ambiguous $U_{\mathrm{k}}$ appeared above the distributor, at $30 \mathrm{~cm}$ and $50 \mathrm{~cm}$.

By wavelet analysis, the energy of the maximum of the approximations indicated the transition velocities, $U_{\mathrm{c}}=1.0 \mathrm{~m} \mathrm{~s}^{-1}$ and $U_{\mathrm{k}}=1.7 \mathrm{~m} \mathrm{~s}^{-1}$.

In conclusion, this study provided several analytical methods to discuss and identify the existence of the transition velocities, especially the new tools, the energy of 

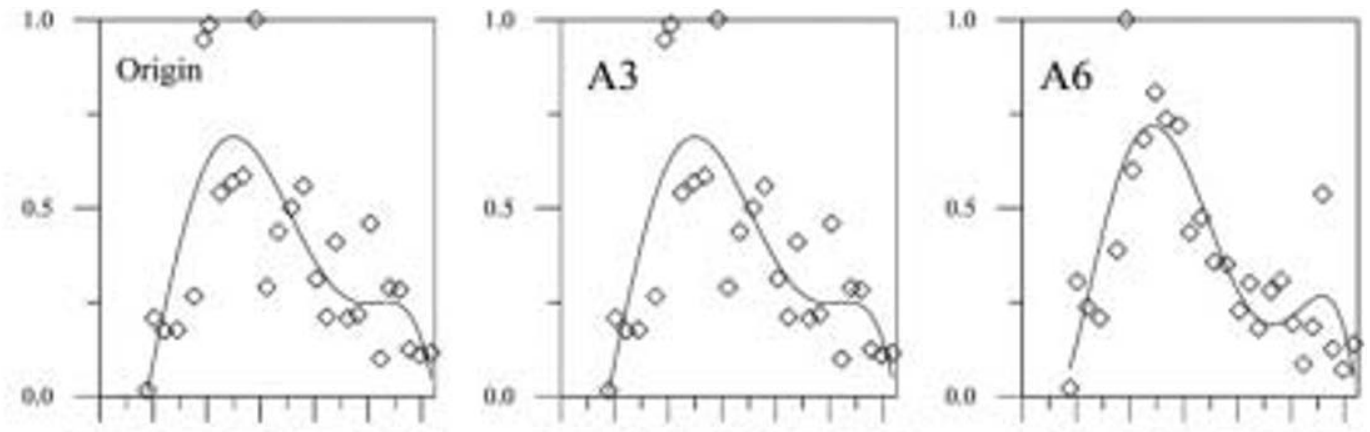

$\begin{array}{llllllll}0.9 & 0.4 & 0.5 & 12 & 16 & 2.0 & 24\end{array}$

$\begin{array}{llllllll}0.0 & 0.4 & 0.8 & 1.2 & 1.6 & 2.0 & 2.4\end{array}$
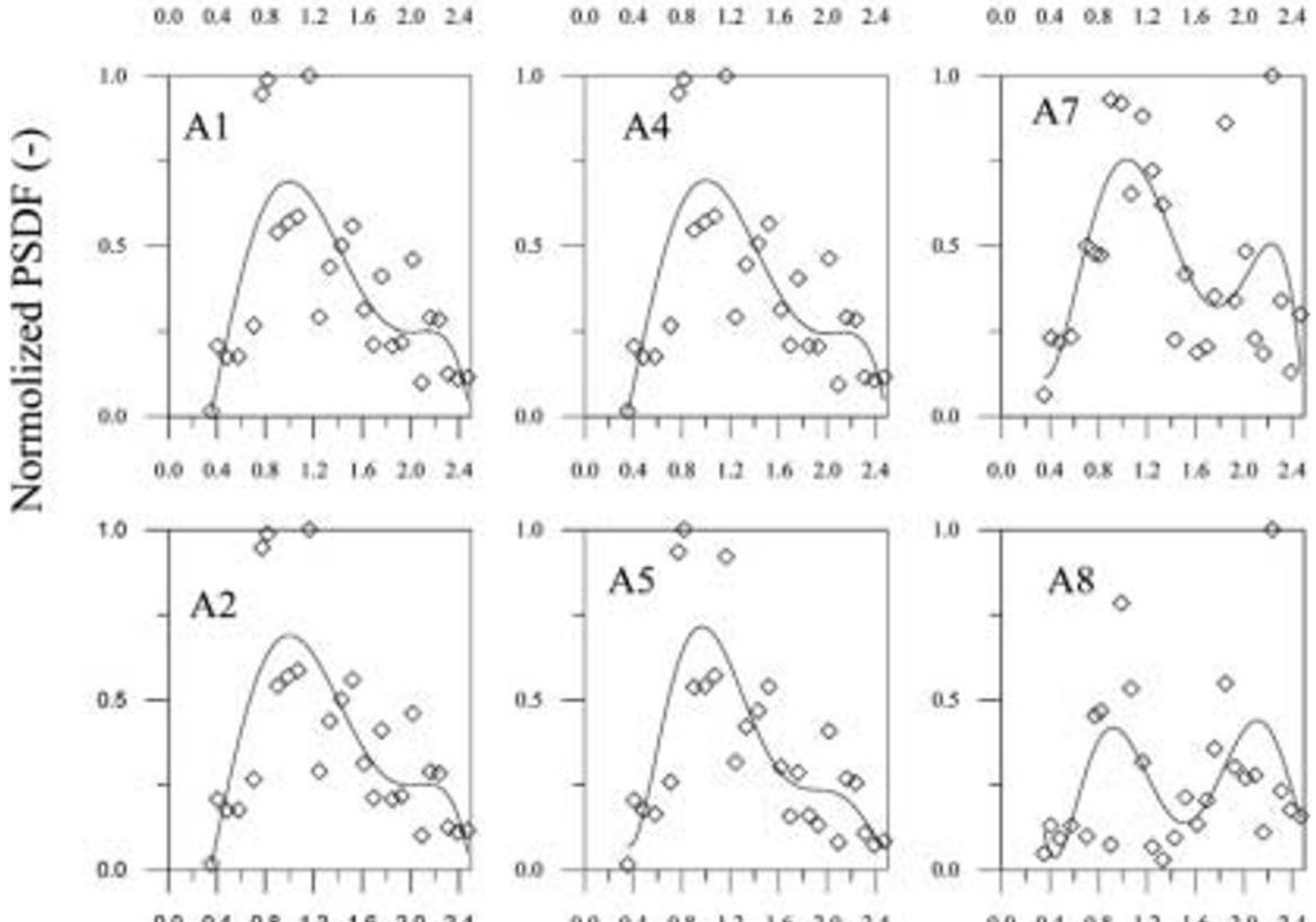

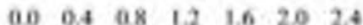
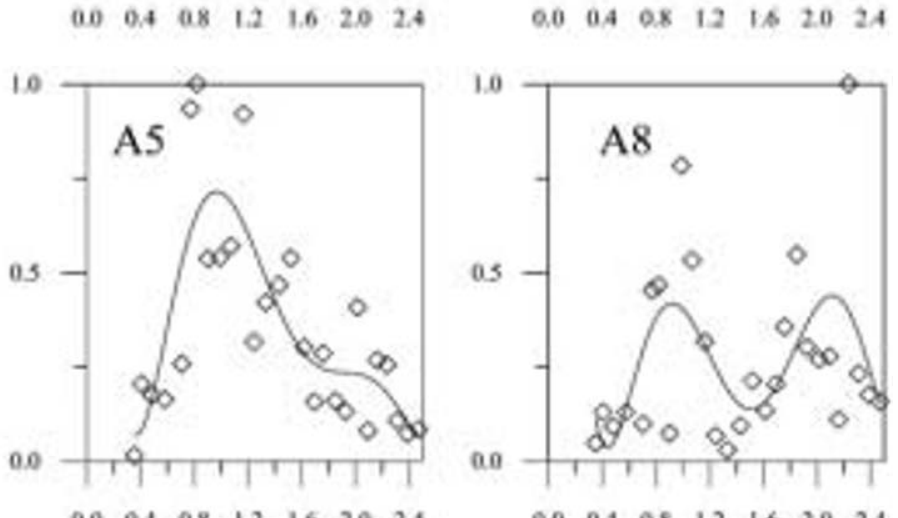

Superficial gas velocity $(\mathrm{m} / \mathrm{s})$

Figure 10. The normalized PSDF of the maximum energy vs. superficial gas velocity, at static bed $60 \mathrm{~cm}$, in height, measured above the distributor at $14 \mathrm{~cm}$ by an absolute pressure probe.

PSDF and wavelet analysis. The result indicated that $U_{\mathrm{c}}$ and $U_{\mathrm{k}}$ could be found above the distributor and below the distributor by absolute pressure measurement.

\section{NOMENCLATURE}

a scale parameter

$A_{\mathrm{j}}\left(t_{\mathrm{i}}\right) \quad$ approximation of multi-resolution decomposition at level $j$

$A_{\mathrm{J}}\left(t_{\mathrm{i}}\right)$

$b$

$d_{\mathrm{p}}$

$D_{\mathrm{j}}\left(t_{\mathrm{i}}\right)$

$e_{\max }$

$e_{\mathrm{MAX}}$

$\overrightarrow{\mathrm{E}}$

$\overrightarrow{\mathrm{E}_{\text {norm. }}}$ f $H_{\mathrm{s}}$

detail of multi-resolution decomposition at level $j$ maximum of energy of the PSDF at the different superficial gas velocities, $\mathrm{Pa}^{2} / \mathrm{Hz}$ an element maximum value of the vector $(\overrightarrow{\mathrm{E}}), e_{\mathrm{MAX}}=$

$\left(e_{\max , 1}, e_{\max .2}, \ldots, e_{\max , \mathrm{n}}\right), \mathrm{Pa}^{2} / \mathrm{Hz}$

the vector of maximum energy of PSDF at different superficial gas velocities, $\overrightarrow{\mathrm{E}}=\left(e_{\max .1}, e_{\max .2}, \ldots\right.$, $\left.e_{\max . \mathrm{n}}\right), \mathrm{Pa}^{2} / \mathrm{Hz}$ normalized the vector of $\overrightarrow{\mathrm{E}}$ by $e_{\mathrm{MAX}} \cdot \overrightarrow{\mathrm{E}_{\text {norm. }}}=$ $\left(e_{\max .1} / e_{\mathrm{MAX}}, e_{\max .2} / e_{\mathrm{MAX}}, \ldots, e_{\max . \mathrm{n}} / e_{\mathrm{MAX}}\right)$ frequency, $\mathrm{Hz}$

static bed height, $\mathrm{m}$

maximum multi-resolution level

integer number

number of sampling point

average of time series of pressure fluctuations, $\mathrm{k} \mathrm{Pa}$

time series of pressure fluctuations, $\mathrm{k} \mathrm{Pa}$

power spectral density function, $\mathrm{Pa}^{2} / \mathrm{Hz}$

power spectral density function (PSDF), $\mathrm{Pa}^{2} / \mathrm{Hz}$

relative wavelet energy distribution in level $J$

(approximation scale), [-]

relative wavelet energy distribution in each level $j$

(detail scale), [-]

autocorrelation function

standard deviation of pressure fluctuations, $\mathrm{k} \mathrm{Pa}$

time, $\mathrm{s}$

the discrete time, $s$

interval time, $\mathrm{s}$

transition velocity at which standard deviation of

pressure fluctuations reaches a maximum, $\mathrm{m} \mathrm{s}^{-1}$ 


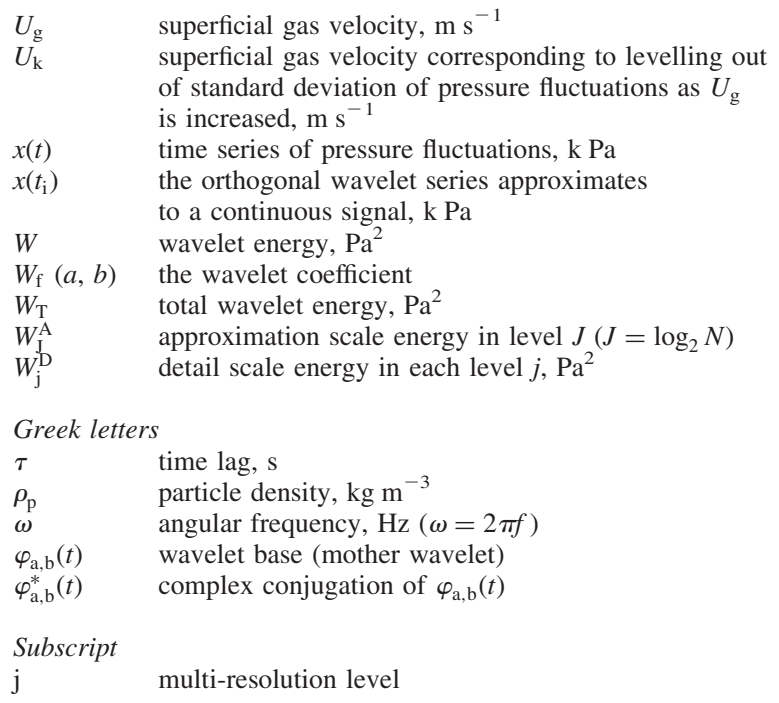

\section{REFERENCES}

Avidan, A.A. and Yerushalmi, J., 1982, Bed expansion in high velocity fluidization, Powder Technol, 32: 223-232.

Avidan, A.A. and Yerushalmi, J., 1985, Solid mixing in an expanded top fluid bed, AIChE J, 31: 835-841.

Bendat, J.S. and Piersol, A.G., 1980, Engineering Applications of Correlation and Spectral Analysis, 47-64 (Wiley, New York, USA).

Bi, H.T. and Grace, J.R., 1995, Effects of measurement method on velocities used to demarcate the transition to turbulent fluidization, Chem Eng J, 57: 261-271.

Bi, H.T., Grace, J.R. and Kim, K.S., 1995, Transition from bubbling to turbulent fluidization, Ind Eng Chem Res, 34: 4003-4008.

Bi, H.T., Ellis, N., Abba, I.A. and Grace, J.R., 2000, A state-of-the-art review of gas-solid turbulent fluidization, Chem Eng Sci, 55: 4789-4825.

Bruce, A. and Gao, H.Y., 1996, Applied Wavelet Analysis with S-Plus, 19-33 (Springer, New York, USA).

Chehbouni, A., Chaouki, J., Guy, C. and Klvana, D., 1994, Characterization of the flow transition between bubbling and turbulent fluidization, Ind Eng Chem Res, 33: 1889-1898.

Fan, L.T., Neogi, D., Yashima, M. and Nassar, R., 1990, Stochastic analysis of a three-phase fluidized bed: fractal approach, AIChE J, 36(10): $1529-1535$.

Geldart, D., 1973, Types of gas fluidization, Powder Technol, 7: 285-292.
Grace, J.R., 2000, Reflections on turbulent fluidization and dense suspension up flow, Powder Technol, 113: 242-248.

Guo, Q., Yue, G. and Werther, J., 2002, Dynamics of pressure fluctuation in a bubbling fluidized bed at high temperature, Ind Eng Chem Res, 41: 3482-3488.

Guo, Q., Yue, G., Suda, T. and Sato, J., 2003, Flow characteristics in a bubbling fluidized bed at elevated temperature, Chem Eng and Processing, 42: 439-447.

He, Z., Zhang, W., He, K. and Chen, B., 1997, Modeling pressure fluctuations via correlation structure in a gas-solid fluidized, AIChE J, 43(7): 1914-1920.

Lanneau, K.P., 1960, Gas-solids contacting in fluidized beds, Trans IChemE, 38: 125-137.

Lee, G.S. and Kim, S.D., 1988, Pressure fluctuations in turbulent fluidized beds, J Chem Eng Japan, 21: 515-521.

$\mathrm{Lu}, \mathrm{X}$. and Li, H., 1999, Wavelet analysis of pressure fluctuation signals in a bubbling fluidized bed, Chem Eng J, 75: 113-119.

Makkawi, Y.T. and Wright, P.C., 2002, Fluidization regimes in a conventional fluidized bed characterized by means of electrical capacitance tomography, Chem Eng Sci, 57: 2411-2437.

Mori, S., Hashimoto, O., Haruta, T., Mochizuki, K., Matsutani, W., Hiraoka, S., Yamada, I., Kojima, T. and Tsuji, K., 1988, Turbulent fluidization phenomena, in Basu, P. and Large, J.F. (eds). Circulating Fluidized Bed Technology II, 105-112 (Pergamon, Oxford, UK).

Park, S.H., Kang, Y. and Kim, S.D., 2001, Wavelet transform analysis of pressure fluctuation signals in a pressurized bubble column, Chem Eng Sci, 56: 6259-6265.

Rhodes, M.J. and Geldart, D., 1986, Transition to turbulence, in Ostergaard, K. and Sorensen, A. (eds). Fluidization V, 281-288 (Engineering Foundation, New York, USA).

Satija, S. and Fan, L.S., 1985, Characteristics of slugging regime and transition to turbulent regime for fluidized beds of large coarse particles, AIChE J, 31: 1554-1562.

Schnitzlein, M.G. and Weinstein, H., 1988, Flow characterization in highvelocity fluidized beds using pressure fluctuations, Chem Eng Sci, 43: $2605-2614$.

Sun, G.L. and Chen, G., 1989, Transition to turbulent fluidization and its prediction, in Grace, J.R., Schemilt, L.W. and Bergougnou, M.A. (eds). Fluidization VI, 33-44 (Engineering Foundation, New York, USA).

Yerushalmi, J., Cankurt, N.T., Geldart, D. and Liss, B., 1978, Flow regimes in vertical gas-solid contact systems, AIChE Symp Ser, 74(176): $1-14$.

Zhao, G.B. and Yang Y.R., 2003, Multiscale resolution of fluidized-bed pressure fluctuations, AIChE J, 49(4): 869-882.

The manuscript was received 19 April 2004 and accepted for publication after revision 9 February 2005. 